\title{
Cardiovascular Disease Recognition through Machine Learning Algorithms
}

\author{
Rajatdeep Kaur, Kamaljit Kaur
}

\begin{abstract}
The heart is more important to the human body than any other circulatory organs. Its function is to provide and pump blood to other organs and brain. So it is very important to have a healthy heart but researches revealed the risk of heart failure increases every day starting from age 30. Many heart specialist can diagnose heart disease with their experience and skills. But some experts lacking the talent or knowledge to predict cardiovascular disease in the early stages, a small mistake can cost a patient's life. Therefore, it is necessary to use specific methods and algorithmic tools to estimate the occurrence of cardiac disorders in the early stages. Different Algorithms for machine learning and data analysis are beneficial in predicting various diseases from patient's data, managed by the Medical Center or hospitals. The data obtained may also help to assess the presence of the disease in the future. Heart Disease or Cardiac related issues can be analyzed by variety of machine learning techniques, Instance Artificial Neural Network, Decision Tree, Random forest, K-nearest neighbor, Nä̈ve Bayes and Support Vector Machine. This study establishes a theoretical understanding of existing algorithms and provides a general understanding of existing work.
\end{abstract}

Keywords: Cardiovascular Disease, Data Mining, Machine Learning.

\section{INTRODUCTION}

Machine Learning is part of the widely used field of Artificial Intelligence that focuses on mimicking humans intellectual abilities by machines [1]. In today's world the volume of data is on the rise, which cannot be ruled out by human involvement as before. Historically, Human Power is used to analyze data, although this method is not systematic but large patterns and data remains hidden [2].Competitive learning theory and model recognition are at the root of Machine Learning. In the field of data analytics these methods are used to predict a business by designing specific models and algorithms. In these ways analysts, scientists, researchers and engineers can produce reliable and valid results. Various hidden patterns or features can also find out past uses and trends in data [1]. Model automation is performed using machine learning methods. In machine learning we have to generate models on the basis of training data and test the model using the test data set. We do not need to teach machines, their functionality allows machines to adapt their methods and produce results depending on new conditions and data [2]. Stages of Machine learning are shown in figure 1.

Revised Manuscript Received on April 25, 2020.

* Correspondence Author

Rajatdeep Kaur*, Department of Computer Engineering and Technology, Guru Nanak Dev University, Amritsar, India. Email: kaur.rajatdeep@gmail.com

Kamaljit Kaur, Department of Computer Engineering and Technology, Guru Nanak Dev University, Amritsar, India. Email: kamal.aujla86@gmail.com

(C) The Authors. Published by Blue Eyes Intelligence Engineering and Sciences Publication (BEIESP). This is an open access article under the CC BY-NC-ND license (http://creativecommons.org/licenses/by-nc-nd/4.0/)

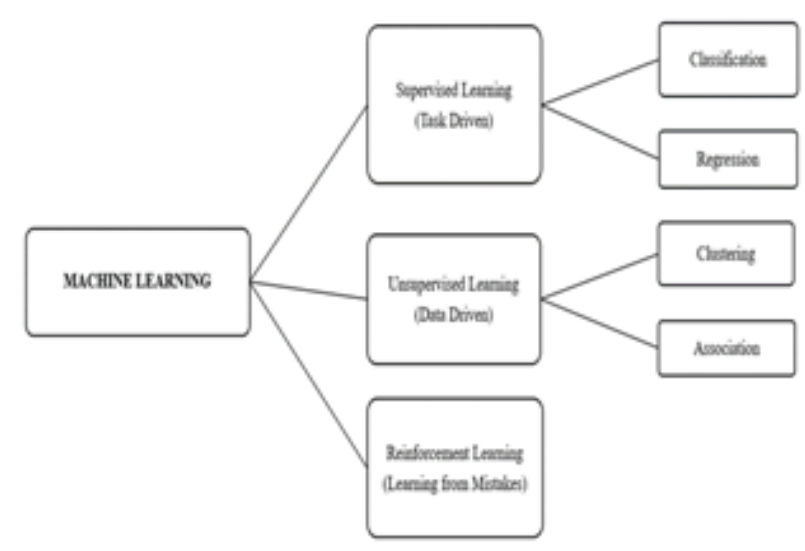

Fig. 1. Stages of Machine Learning

\section{A. Supervised Learning}

In supervised learning, Input and Output variables are provided to model for its training and allow it to analysis the relationship between these values. Then the model is expected to predict the unknown variables based on training of model. Classification and Regression are other strategies in supervised learning based on predicted variables. In regression problem, the estimated values are continuous and if the theoretical prediction comes from independent variables, called classes, it is known as the classification problem. Here are some supervised learning algorithms [1]:

- $\quad$ Support Vector Machine

- Decision Tree

- $\quad$ Naïve Bayes

- Random Forest

\section{B. Unsupervised Learning}

The purpose in unsupervised learning is to explore unknown styles. Information is organized in groups that do not have related labels. Cluster Analysis and Dimensionality Reduction are some of the least explored learning models At Cluster we have the same intra cluster similarity and the less inter cluster similarity. In dimension Reduction, replicated and unwanted variables are emitted to generate a smaller subset of the original data [1].

\section{Reinforcement Learning}

In this kind of machine learning environment, Machine is trained in such a way that it will take appropriate steps to maximize the rewards in a given situation. Various software and machines are used to find the possible method or behavior must be taken in a particular situation.

\section{Published By:}

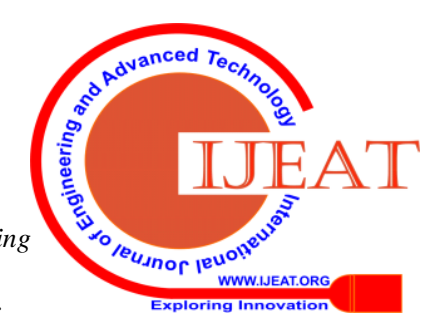


In this machine you will definitely learn from what happened [3].

Machine Learning and Cardiovascular Problems: Various Medical Centers use machine learning methods to diagnose and predict problems or diseases, e.g. prediction of cancer or heart disease. Clinical parameters or data can be obtained from various health facilities and hospitals.

A major cause of human deterioration is heart disease. It is analyzed that about 17.5 million people are died due to heart illness [4]. The heart is a major part of our body and our health depends on the functioning of the heart. Heart failure can affect cardiac function [5]. Due to the rapid growth of digital technology, medical centers save chunks of data in their repositories, which becomes difficult to analysis. The process of data mining and Machine learning algorithms paly major contribution to dissect the non-identical content in medical institutions. These techniques and algorithms can work on a dataset to generate models and draw conclusions from them. Common features used to detect cardiovascular disease as shown in table I, are Age of the patient, Gender, High blood pressure, Type of Chest Pain, ECG (test used to measure cardiac electrical activity), Number of excellent fluoroscopy, Hypertension, High Cholesterol, Thalach (high-risk coronary heart disease), ST pressure (detected on the electrocardiogram), painloc (chest pain area), Accelerating level of blood sugar, smoking status, eating habits, BMI and obesity as listed below for their symptoms [6].

Table- I: Factors responsible for heart disease [6] and its symptoms [7].

\begin{tabular}{|c|c|c|}
\hline Risk Factors & Description & $\begin{array}{c}\text { General } \\
\text { Symptoms: }\end{array}$ \\
\hline Age & $\begin{array}{l}\text { The risk of heart } \\
\text { disease increases with } \\
\text { age. }\end{array}$ & \multirow{4}{*}{$\begin{array}{c}\text { Chest pain, } \\
\begin{array}{c}\text { Shortness of } \\
\text { breath, }\end{array} \\
\text { Abnormal } \\
\text { heartbeat, }\end{array}$} \\
\hline Gender & $\begin{array}{l}\text { Men have a higher risk } \\
\text { of having a heart } \\
\text { problem than women }\end{array}$ & \\
\hline $\begin{array}{l}\text { Family } \\
\text { History }\end{array}$ & $\begin{array}{l}\text { Sometimes inherited. If } \\
\text { blood-related relatives } \\
\text { have heart disease then } \\
\text { the chances of heart } \\
\text { problems in a person } \\
\text { increase. }\end{array}$ & \\
\hline Smoking & $\begin{array}{l}\text { Smokers have a higher } \\
\text { rate of heart disease } \\
\text { than non-smokers. }\end{array}$ & \\
\hline
\end{tabular}

\begin{tabular}{|c|c|c|}
\hline Bad Food & $\begin{array}{l}\text { Proper diet is very } \\
\text { important for } \\
\text { development of } \\
\text { healthy heart. }\end{array}$ & \\
\hline $\begin{array}{l}\text { High blood } \\
\text { pressure }\end{array}$ & $\begin{array}{l}\text { The arterial blood } \\
\text { vessels are affected by } \\
\text { Blood Pressure [6], [7]. }\end{array}$ & \\
\hline $\begin{array}{l}\text { Higher } \\
\text { cholesterol } \\
\text { levels }\end{array}$ & $\begin{array}{ll}\text { Plaque } & \text { formation } \\
\text { increases } & \end{array}$ & $\begin{array}{l}\text { Fatigue, } \\
\text { Fainting, }\end{array}$ \\
\hline Diabetes & $\begin{array}{l}\text { Patient suffers Diabetes } \\
\text { has a high risk of heart } \\
\text { disease }\end{array}$ & Swollen feet. \\
\hline Obesity & $\begin{array}{l}\text { Obesity is a major } \\
\text { cause of heart disease. }\end{array}$ & \\
\hline $\begin{array}{l}\text { Physical } \\
\text { inactivity }\end{array}$ & $\begin{array}{l}\text { Physical activities are } \\
\text { needed for the heart to } \\
\text { function properly. }\end{array}$ & \\
\hline Stress & $\begin{array}{l}\text { Pressure May damage } \\
\text { the blood vessels }\end{array}$ & \\
\hline Hygiene & $\begin{array}{l}\text { Poor hygiene Increases } \\
\text { heart disease }\end{array}$ & \\
\hline
\end{tabular}

Table- II: The most common types of heart disease [8]

\begin{tabular}{|l|l|}
\hline \multicolumn{1}{|c|}{ Type } & \multicolumn{1}{|c|}{ Effects } \\
\hline Arrhythmia & $\begin{array}{l}\text { Improper heartbeat, even if it is not } \\
\text { accompanied, very slow or very fast. }\end{array}$ \\
\hline Cardiac arrest & $\begin{array}{l}\text { The heart stops working, feelings of } \\
\text { worthlessness and loss of breath occur } \\
\text { frequently and suddenly. }\end{array}$ \\
\hline $\begin{array}{l}\text { Congestive heart } \\
\text { disorder }\end{array}$ & $\begin{array}{l}\text { The heart cannot pump blood and supply } \\
\text { essential nutrients and oxygen to other } \\
\text { organs according to need. }\end{array}$ \\
\hline $\begin{array}{l}\text { Congenital heart } \\
\text { disease }\end{array}$ & Cardiac abnormalities. \\
\hline
\end{tabular}




\begin{tabular}{|l|l|}
\hline $\begin{array}{l}\text { Coronary artery } \\
\text { disorder }\end{array}$ & $\begin{array}{l}\text { The most important blood vein can } \\
\text { damage any disease in the blood vessels. }\end{array}$ \\
\hline High BP & $\begin{array}{l}\text { Pressure is applied on the blood veins } \\
\text { while passing through them. }\end{array}$ \\
\hline $\begin{array}{l}\text { Peripheral artery } \\
\text { disease }\end{array}$ & $\begin{array}{l}\text { The arterial blood vessels that slow the } \\
\text { flow of blood to the legs. }\end{array}$ \\
\hline Stroke & $\begin{array}{l}\text { Interruption of blood supply occurs to the } \\
\text { brain. }\end{array}$ \\
\hline
\end{tabular}

\section{LITERATURE REVIEW}

Ample work has suggested the use of different Data Mining (DM) techniques and Machine Learning (ML) algorithms in clinical centers used to measure Heart disease. Table III shows the parametric analysis of existing literature.

Marjia Sultana, Afrin Haider, Mohammad Shorif Uddin [9] proposed a model to predict heart disease using K-Star, J-48, SMO, Bayes Net (BN) and MLP programs in the WEKA (Waikato Environment for Knowledge Analysis) software. The UCI Machine Learning Repository is a source of data containing 270 records of which some are non-cardiac data and other are cardiovascular data. SMO and Bayes Network performs much better than the other three separators. The tests performed are based on K-fold cross validation (where $\mathrm{k}=10)$.To provide the best diagnostic decision for diagnostic performance the accuracy needs to be improved.

Kanak Saxena, Richa Sharma [10] develop a functional cardiac prediction system using a decision tree. The University of California, Irvine and Cleveland Clinic Foundation are used for data collection and Dataset testing was performed using WEKA software and Order selection criteria were obtained using KEEL. Specialists and individuals in the field can make an effective decision on the basis of specific symptoms using this technique. The 10 fold method is used for testing and training the system and the accuracy for testing phase is $86.3 \%$ and the same for training phase is $87.3 \%$.

Chala Beyene, Pooja Kamat [11] introduced a system for automatic cardiovascular disease monitoring. The program presented helps professionals with less experience and skills. ML algorithms such as the J-48, NB and SVM with K-fold Cross-proofing are used to achieve the appearance of heart failure. Distinguishing medical features such as blood sugar, age, sex and many more are useful to check whether a person has heart disease or not. Data set analysis was performed by WEKA software.

Ashok Dwivedi [12] uses different algorithms like Naïve Bayes (NB), Classification Tree, K-nearest neighbor (KNN), Linear Regression (LR), Support Vector Machine (SVM) and Artificial Neural Network (ANN) to predict heart disease. The Statlog heart disease Dataset found at UCI is used for this study. The study comprises 270 total characteristics of which 150 are free of cardiovascular disorders and 120 have cardiac disorders, while 13 different parameters are considered. Each algorithm have different accuracy, but the Logistic Regression has better value than all the different ML methods with a high accuracy of $85 \%$ and the ANN obtained the second highest accuracy.
S. Seema, Deepika kumari [13] focusing on Decision Tree (DT), NB, SVM and ANN to study the heart attack database available at UCI repositories. To calculate the optimal performance at an accurate rate, a comparative analysis was performed. In this study, it is clear that absolute accuracy i.e. $95.2 \%$ is obtained from SVM and the second highest accuracy i.e. $94.27 \%$ is available from ANN and DT has the lowest accuracy among all.

K. Polaraju, D.Durga Parsad [14] using the Multiple Regression Model for the diagnosis of cardiovascular disease by looking at different patient characteristics. The test is performed on a training data set that has 3000 attributes and the data splits in 7:3 ratio. It is understandable from the results that the Regression Algorithm had a better classification accuracy compared to others and showed that Multiple Linear Regression is better for predicting heart disease.

Jayami Patel, Tejpal Upadhyay, Samir Patel [15] compare the different techniques of DT classification looking for higher interpretations in prognosis of heart disease with the use of WEKA software. It uses J-48, Logistic Model Tree (LMT) and RF for comparisons and uses UCI data that creates cases containing 303 cases and 76 symbols. The purpose of this study, is to use data mining techniques to extract hidden patterns. The highest accuracy is obtained from the J-48 i.e. $56.76 \%$ and low LMT i.e. $55.77 \%$. Cardiac prediction is improved by using a combination of algorithms and using more sophisticated models.

S. Prabhavathi, DM Chitra [16] introduced a systematic approach to controlling and extracting the estimated form of successful initiation of a heart attack from data sets of heart attacks. The first aim of this study is to overcome the limitations of the existing system by building a smart and expensive system. Different types of cardiovascular diseases such as CAD, CVD and CHD are predicted using the Decision Tree based Neural Fuzzy System (DNFS) techniques. The proposed system used Data Mining techniques to improve prediction of heart disease, using various data mining techniques. C4.5 performs well for CAD detection and SVM and Neural Network responds well for CHD detection. But the decision tree method is good classifier to diagnose CVD heart disease (after a factor was extracted using GA). As a result of this research study and feature reduction using GA or Principal Component analysis (PCA) can increase the accuracy of the classifier. However, DT and NB classifier are highly recommended for CVD to predict better accuracy.

Sairabi H.Mujawar, PR Devale [17] suggested DM techniques, such as NB and Modified K-methods for analyzing cardiovascular disease. The Cleveland Database for Cardiovascular Disease is used to have 300 records with 13 symptoms. The proposed model to predict the occurrence of heart attack or not and after proper analysis on the diagnosis, doctors may recommend other tests. The classification and clustering techniques are used for prognosis and the modified K-means algorithm is proposed to overcome the limit of the K-means algorithm, which needs to be integrated as input. 
R. Sharmila, S. Chllammal [18] proposed a method based on Hadoop and Map Reducing programming. It uses support vector machine (SVM) in the same way to improve predictive accuracy. This study proposed using non-linear classical algorithms that provide better accuracy from which the SVM works best.

M Akhil Jabbar, Bulusu Lakshmana Deekshatulu, Priti Chandra [19], used the Random forest method and Chi Square to estimate cardiovascular disease. The proposed model was tested using different databases such as data collected from various hospitals in Hyderabad, Cleveland and Stalog data. Accurate and alternative methods have been used to make comparisons between the various $\mathrm{ML}$ algorithms that were PART C4.5, Naïve Bayes, Decision Table, Neural nets, and Random Forest among which proposed method (Random Forest + Chi Square) has better accuracy.

Yeshvendra K Singh, Nikhil Sinha, Sanjay K Singh [20], Random forest was used to predict cardiovascular disease. The efficacy of the proposed method is evaluated using the Cleveland Heart Disease Dataset and the 10 fold cross validation was performed to verify the authentication of accuracy which is achieved as $85.81 \%$.

Amin UI Haq, Jain Ping Li, Muhammad Hammad Memon, Shah Nazir, Ruinan Sun [21], developed an HD diagnostic system using other ML and Feature Selection Algorithms. Various performance metrics such as category accuracy, precision, sensitivity, Mathew accuracy and performance time are analyzed. The proposed system compared performance on full features, and reduced features and calculated that results on feature reduction data have better accuracy and reduced execution time.

Subhashini Narayan, E Sathiyamoorthy [22], used the Fourier Transform and Machine Learning Machine to accurately predict chronic diseases. The proposed system used a bootstrap model and three different algorithms namely ANN, NB and SVM for evaluation.

Abderrahmane Ed- Daoudy, Khalil Maalmi [23], presented an RT-HD prognosis program based on Apache Spark. The program consists of various stages such as stream broadcasting and DS and visualization. Spark MLlib for spark propagation was used for streaming processing and Apache Cassandra was used by DS and Visualization to accumulate a large amount of data.

Abdar et al. [24], introduced a new N2-Genetic Optimizer system that uses SVM integration with GA or PSO. In this paper various ML Algorithms were used to evaluate the ZAlizadeh Saini cardiovascular disease, out of which SVM is best selection method and was used for further experiments. Preparation of data reconstruction was performed using Normalization and GA or PSO was used for feature selection and minimization of asset replication. As a result of this process the GA + nuSVM has better accuracy than the PSO + nuSVM in both test and training data.

Miray Akgul, Ozlen Ekal Sonmez, Tunacy Ozcan [25], uses the Artificial Neural Network to monitor the Heart Problem using the default parameters. Subsequently, the combination of GA (Genetic Algorithm) and ANN (Artificial Neural Network), tested a hybrid method using the cardiac database 'Cleveland' and obtained better accuracy than ANN and other ML algorithms.

Table- III: A Parametric Analysis of Existing Literature

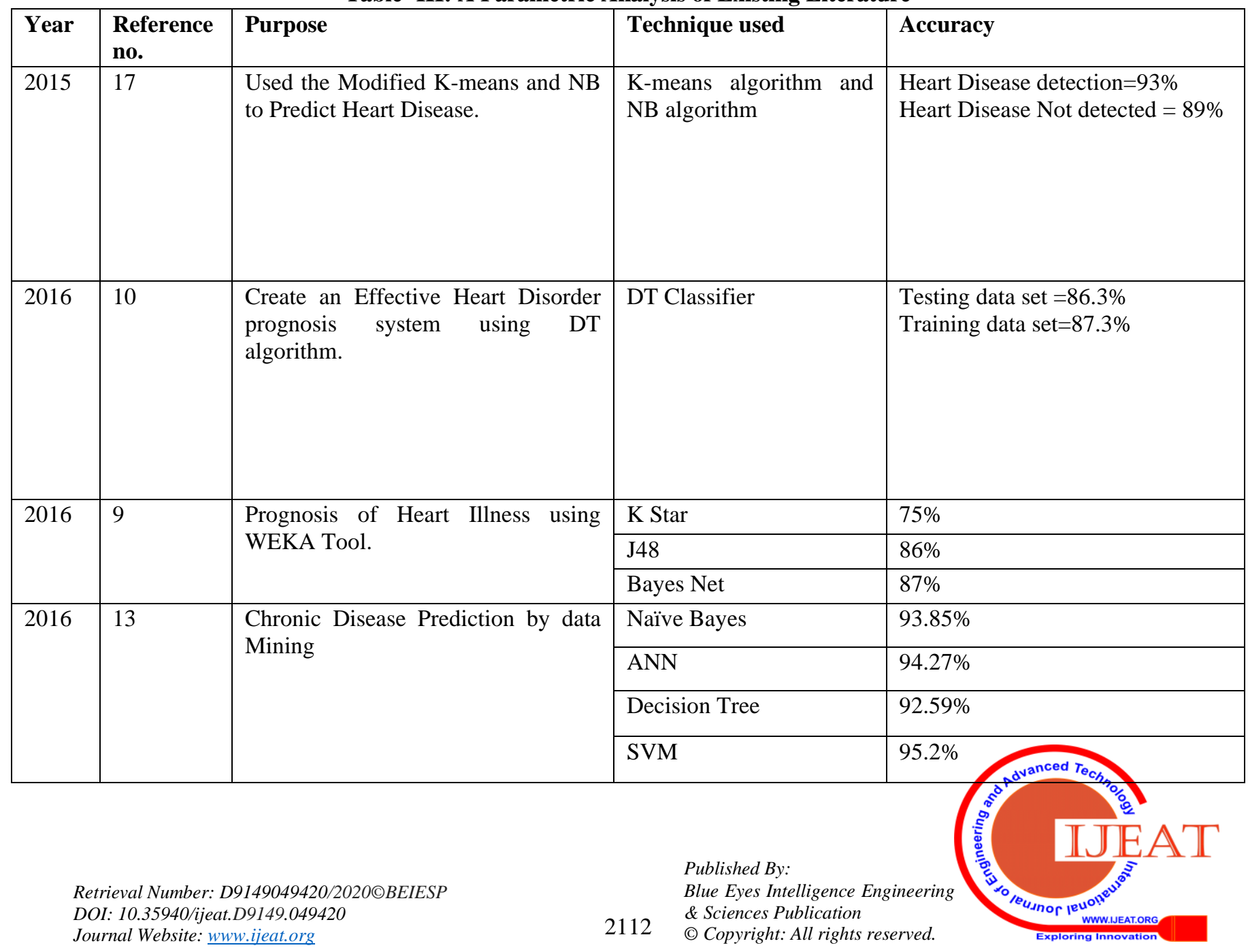




\begin{tabular}{|c|c|c|c|c|}
\hline \multirow[t]{4}{*}{2016} & \multirow[t]{4}{*}{12} & \multirow{4}{*}{$\begin{array}{l}\text { Assess the execution of distinct ML } \\
\text { algorithms for Heart Illness } \\
\text { Prognosis. }\end{array}$} & NB & $83 \%$ \\
\hline & & & KNN & $80 \%$ \\
\hline & & & $\begin{array}{ll}\text { LR } \\
\end{array}$ & $85 \%$ \\
\hline & & & Classification Tree & $77 \%$ \\
\hline \multirow[t]{2}{*}{2016} & \multirow[t]{2}{*}{15} & \multirow[t]{2}{*}{$\begin{array}{l}\text { ML and DM Techniques are used to } \\
\text { predict Heart Disease. }\end{array}$} & $\mathrm{J} 48$ & $56.76 \%$ \\
\hline & & & Logistic Model Tree & $55.75 \%$ \\
\hline 2016 & 16 & $\begin{array}{l}\text { DNFS Techniques are used to } \\
\text { Analysis and Predict different Heart } \\
\text { disorders. }\end{array}$ & DT, c4.5, SVM, NB & $\begin{array}{l}85 \% \text { to } 99 \% \text { for CVD } \\
82 \% \text { to } 92 \% \text { for } C H D\end{array}$ \\
\hline \multirow[t]{5}{*}{2016} & \multirow[t]{5}{*}{19} & \multirow{5}{*}{$\begin{array}{l}\text { Use of Random Forest and Feature } \\
\text { Selection for prediction of Heart } \\
\text { Disease }\end{array}$} & $\begin{array}{l}\text { Random Forest and Chi } \\
\text { Square }\end{array}$ & $83.70 \%$ \\
\hline & & & Naïve Bayes & $78.56 \%$ \\
\hline & & & Decision Tree & $82.43 \%$ \\
\hline & & & PART C4.5 & $75.4 \%$ \\
\hline & & & Neural nets & $82.77 \%$ \\
\hline 2016 & 20 & $\begin{array}{lccc}\text { Heart Disease } & \text { prediction } & \text { using } \\
\text { Random Forest } & & \\
\end{array}$ & Random Forest & 85.81 \\
\hline 2018 & 11 & $\begin{array}{l}\text { Use of DM Techniques to Predict } \\
\text { and Analysis the happening of Heart } \\
\text { Disorders. }\end{array}$ & J48, NB, SVM & $\begin{array}{l}\text { The result helps to lessen the cost } \\
\text { of diagnosis and provides } \\
\text { appropriate results }\end{array}$ \\
\hline 2018 & 18 & $\begin{array}{l}\text { Big Data and DM techniques can } \\
\text { intensify the prognosis of Heart } \\
\text { Disorders. }\end{array}$ & SVM in parallel fashion & $\begin{array}{l}\text { Parallel SVM }=85 \% \quad \text { and } \\
\text { Sequential SVM }=82.35 \% \text {. }\end{array}$ \\
\hline \multirow[t]{6}{*}{2018} & \multirow[t]{6}{*}{21} & \multirow{6}{*}{$\begin{array}{l}\text { Hybrid Framework of Feature } \\
\text { selection and Machine Learning for } \\
\text { the prediction of heart illness }\end{array}$} & Logistic Regression & $84 \%$ \\
\hline & & & SVM & $86 \%$ \\
\hline & & & Naïve Bayes & $83 \%$ \\
\hline & & & Artificial Neural Network & $73 \%$ \\
\hline & & & Decision Tree Classifier & $74 \%$ \\
\hline & & & K- Nearest Neighbor & $83 \%$ \\
\hline 2018 & 22 & $\begin{array}{l}\text { FFT based system with Machine } \\
\text { Learning for predicting and Identify } \\
\text { Heart Disease }\end{array}$ & $\begin{array}{l}\text { Fourier Transformation } \\
\text { and Machine Learning }\end{array}$ & $93 \%$ \\
\hline 2019 & 23 & $\begin{array}{l}\text { Early detection of heart disease using } \\
\text { real time Machine Learning and Big } \\
\text { data Approach. }\end{array}$ & $\begin{array}{l}\text { Big Data }+ \text { Machine } \\
\text { Learning }\end{array}$ & $87.50 \%$ \\
\hline \multirow[t]{2}{*}{2019} & \multirow[t]{2}{*}{24} & \multirow{2}{*}{$\begin{array}{l}\text { Accurate Diagnoses of CAD using } \\
\text { Machine Learning Approach }\end{array}$} & GA+SVM & $93.08 \%$ \\
\hline & & & PSO + SVM & $91.13 \%$ \\
\hline 2019 & 25 & $\begin{array}{l}\text { Hybrid ANN and GA approach for } \\
\text { heart disease diagnosis }\end{array}$ & $\mathrm{GA}+\mathrm{ANN}$ & $95.82 \%$ \\
\hline
\end{tabular}




\section{RESULT ANALYSIS}

Various algorithms were used for the prediction of heart disease, it is analyzed from above literature work that each algorithm results into different performance accuracy that effects the outcome of a proposed model. As shown in Figure 2 and Table IV, SVM depicts the highest accuracy among all classifiers, whereas KNN has the lowest performance.

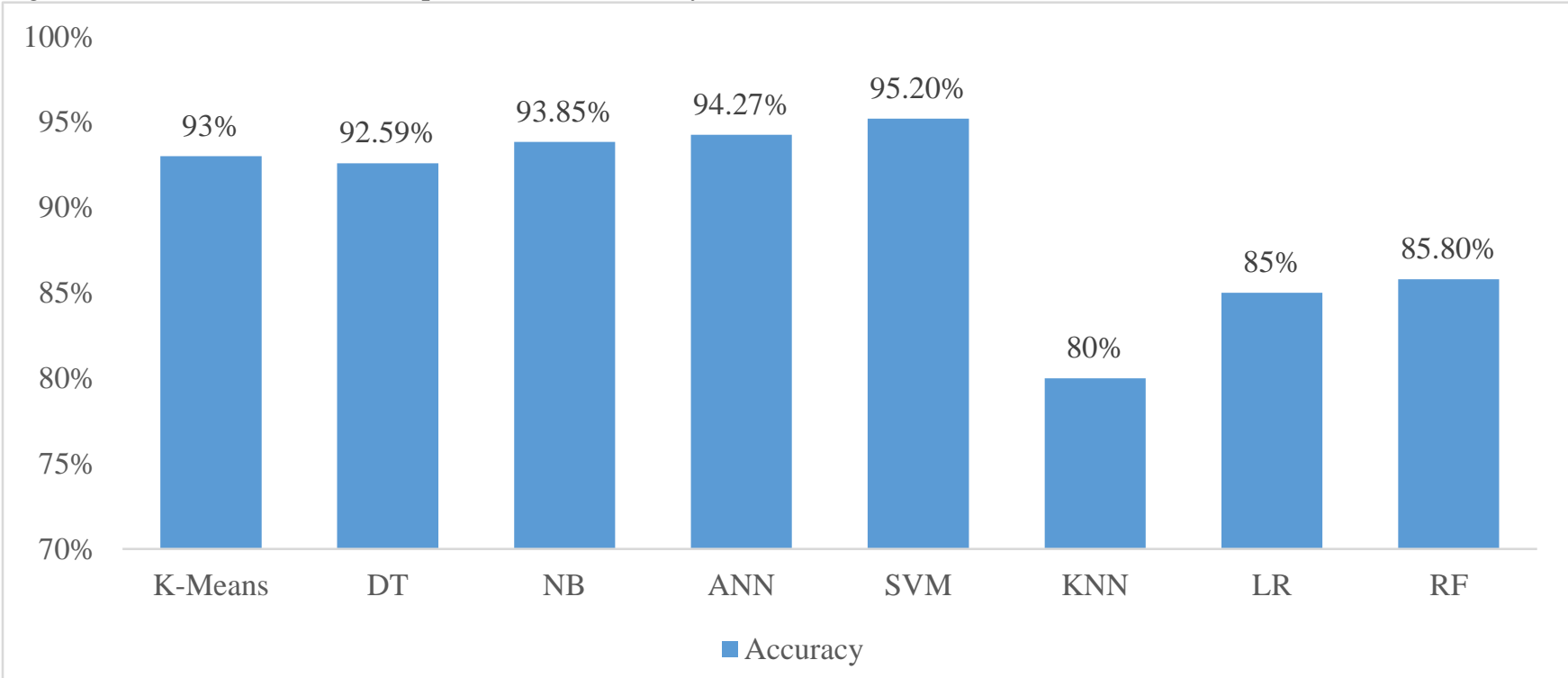

Fig. 2. Shows the performance of Machine Learning Algorithms

Table-IV: Performance of Various Machine Learning Algorithms to detect heart disease.

\begin{tabular}{|l|l|}
\hline Algorithm & $\begin{array}{l}\text { Accuracy (in } \\
\text { Percentage) }\end{array}$ \\
\hline K-Means & $93 \%$ \\
\hline Decision Tree & $92.59 \%$ \\
\hline Naïve Bayes & $93.85 \%$ \\
\hline $\begin{array}{l}\text { Artificial Neural } \\
\text { Network }\end{array}$ & $94.27 \%$ \\
\hline Support Vector Machine & $95.20 \%$ \\
\hline K- Nearest Neighbor & $80 \%$ \\
\hline Linear Regression & $85 \%$ \\
\hline Random Forest & 85.80 \\
\hline
\end{tabular}

The accuracy of SVM is observed as $95.20 \%$, however the accuracy of other algorithms that are K-Means, Decision Tree, Naïve Bayes and Artificial Neural Network is fluctuating from $92.59 \%$ to $94.27 \%$. While other algorithms have accuracy less than 90\%. Cardiovascular disease can easily predict from the model having best performance.

\section{CONCLUSION}

It is recognized that many data mining and machine learning algorithms are used to examine the presence of cardiac disorders using different data sets. It is analyzed that SVM is the most efficient and KNN has the least accuracy. The results can be improved by using proper feature selection methods. Better and more accurate results can help local specialists and others associated with the field be better prepared for high quality care and provide the patient with the right treatment. So early detection helps to provide quality service and saves the health of the individual.

\section{REFERENCES:}

1. Rätsch, Gunnar. "A brief introduction into machine learning." Friedrich Miescher Laboratory of the Max Planck Society (2004).

2. Alpaydin, Ethem. Introduction to machine learning. MIT press, 2020.

3. Sutton, Richard S. "Introduction: The challenge of reinforcement learning." In Reinforcement Learning, pp. 1-3. Springer, Boston, MA 1992.

4. Learning, Machine. "Heart Disease Diagnosis and Prediction Using Machine Learning and Data Mining Techniques: A Review." Advances in Computational Sciences and Technology 10, no. 7 (2017): 2137-2159

5. Krishnaiah, V., G. Narsimha, and N. Subhash Chandra. "Heart disease prediction system using data mining techniques and intelligent fuzzy approach: A review." International Journal of Computer Applications 136, no. 2 (2016): 43-51

6. Srinivas, K., G. Raghavendra Rao, and A. Govardhan. "Survey on prediction of heart morbidity using data mining techniques." International Journal of Data Mining \& Knowledge Management Process (IJDKP) 1, no. 3 (2011): 14-34.

7. Heart Disease symptoms caused by heart infections http://www.mayoclinic.org/diseasesconditions/heartdisease/symptoms-causes/dxc-20341558

8. Types of Heart Disease that effect different organs https://www.medicalnewstoday.com/articles/237191

9. Sultana, Marjia, Afrin Haider, and Mohammad Shorif Uddin. "Analysis of data mining techniques for heart disease prediction." In 2016 3rd International Conference on Electrical Engineering and Information Communication Technology (ICEEICT), pp. 1-5. IEEE, 2016.

10. Saxena, Kanak, and Richa Sharma. "Efficient heart disease prediction system using decision tree. "In International Conference on Computing, Communication \& Automation, pp.72-77. IEEE, 2015

\section{Published By:}

$$
\begin{aligned}
& \text { \& Sciences Publication } \\
& \text { (C) Copyright: All rights reserved. }
\end{aligned}
$$


11. Beyene, Mr Chala, and Pooja Kamat. "Survey on Prediction and Analysis the Occurrence of Heart Disease Using Data Mining Techniques." International Journal of Pure and Applied Mathematics 118, no. 8 (2018): 165-174.

12. Dwivedi, Ashok Kumar. "Performance evaluation of different machine learning techniques for prediction of heart disease." Neural Computing and Applications 29 (2016): 685-693.

13. Deepika, Kumari, and S. Seema. "Predictive analytics to prevent and control chronic diseases." In 2016 2nd International Conference on Applied and Theoretical Computing and Communication Technology (iCATccT), pp. 381-386. IEEE, 2016.

14. K Polaraju, D.Durga Prasad, "Prediction of Heart Disease using Multiple Linear Regression Model", International Journal of Engineering Development and Research (IJEDR), ISSN:2321-9939, Volume.5, Issue 4, pp.1419-1425, December 2017

15. Patel, Jaymin. "Prof. Tejal Upadhyay, and Dr. Samir Patel, Sep 2015Mar 2016,“." Heart Disease Prediction using Machine Learning and Data Mining Technique 7, no. 1: 129-137.

16. Prabhavathi, S., and D. M. Chitra. "Jan. 2016,"Analysis and Prediction of Various Heart Diseases using DNFS Techniques"." International Journal of Innovations in Scientific and Engineering Research (IJISER) 2, no. 1: 1-7.

17. Mujawar, Sairabi H., and P. R. Devale. "Prediction of Heart Disease using Modified K-means and by using Naïve Bayes." International Journal of Innovative research in Computer and Communication Engineering 3 (2015): 10265-10273.

18. R. Sharmila, S. Chellammal, "A conceptual method to enhance the prediction of heart diseases using big data Techniques", International Journal of Computer Sciences and Engineering, Vol.06, Issue.04, pp.21-25, 2018.

19. Jabbar, M. Akhil, Bulusu Lakshmana Deekshatulu, and Prit Chandra. "Prediction of heart disease using random forest and feature subset selection." In Innovations in Bio-Inspired Computing and Applications, pp. 187-196. Springer, Cham, 2016.

20. Singh, Yeshvendra K., Nikhil Sinha, and Sanjay K. Singh. "Heart Disease Prediction System Using Random Forest." In International Conference on Advances in Computing and Data Sciences, pp. 613623. Springer, Singapore, 2016.

21. HAQ, Amin Ul, et al. A hybrid intelligent system framework for the prediction of heart disease using machine learning algorithms. Mobile Information Systems, 2018, 2018.

22. NARAYAN, Subhashini; SATHIYAMOORTHY, E. A novel recommender system based on FFT with machine learning for predicting and identifying heart diseases. Neural Computing and Applications, 2019, 31.1: 93-102.

23. ED-DAOUDY, Abderrahmane; MAALMI, Khalil. Real-time machine learning for early detection of heart disease using big data approach. In: 2019 International Conference on Wireless Technologies, Embedded and Intelligent Systems (WITS). IEEE, 2019. p. 1-5.

24. Abdar, Moloud, Wojciech Książek, U. Rajendra Acharya, Ru-San Tan, Vladimir Makarenkov, and Paweł Pławiak. "A new machine learning technique for an accurate diagnosis of coronary artery disease." Computer methods and programs in biomedicine 179 (2019): 104992.

25. Akgül, Miray, Özlen Erkal Sönmez, and Tuncay Özcan. "Diagnosis of Heart Disease Using an Intelligent Method: A Hybrid ANN-GA Approach." In International Conference on Intelligent and Fuzzy Systems, pp. 1250-1257. Springer, Cham, 2019.

\section{AUTHORS PROFILE}

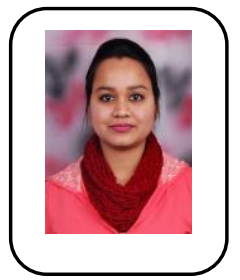

Rajatdeep Kaur, is a student of Masters of Technology, Computer Engineering and Technology at Guru Nanak Dev University, Amritsar, India. Her main research area is Machine Learning and Data Mining. She is Gold medalist in Bachler's of Technology from Global Institutes of Management and Emerging Technologies, Amritsar, India.

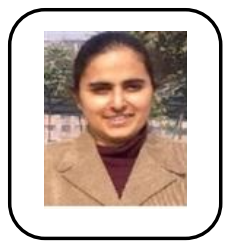

Kamaljit Kaur, was born in Kapurthala, Punjab, India. She completed B.Tech with Distinction from Punjab Technical University, and M.Tech with Gold Medal from Guru Nanak Dev University, Amritsar. She has submitted $\mathrm{PhD}$ in the field of Cloud Computing from Guru Nanak Dev University, Amritsar. From 2007 to 2008 she was employed with
Dr. B.R Ambedkar NIT, Jalandhar as Lecturer and from 2010 to 2012, she worked as an assistant professor at Lovely Professional University, Jalandhar. She joined Guru Nanak Dev University, Amritsar in July 2012 where she is currently working as Assistant Professor. Her research Interests are in Resource Provisioning in Cloud Computing, Resiliency in Cloud Computing and Distributed Systems, Big Data, IoT. Kamaljit Kaur has published and presented more than 45 papers in scientific journals and international conferences. 